[RAdIocarbon, Vol 22, No. 2, 1980, P 318-327]

\title{
THE CONCEPT OF DC GAIN IN MODELING SECULAR VARIATIONS IN ATMOSPHERIC ${ }^{14} \mathrm{C}$
}

\author{
GREGORY LAZEAR*, PAUL E DAMON, \\ and ROBERT STERNBERG
}

Laboratory of Isotope Geochemistry, Department of Geosciences, University of Arizona, Tucson, Arizona, 85719

\begin{abstract}
A constraint on radiocarbon reservoir models is that the DC gain of a system (system transfer function at zero frequency) should equal the equilibrium ratio of the atmospheric radiocarbon mass to the production rate. The simple one-box model is essentially a "black box" but the value of the single residence time is theoretically equal to the DC gain. Using a sunspot-production rate algorithm as the forcing function, predictions of the one-box model match the ${ }^{14} \mathrm{C}$ data from AD 1700 to 1900 better than the 3-box, 5-box and box-diffusion models. The more complex models tend to pile up ${ }^{14} \mathrm{C}$ in the atmosphere because their DC gains are too high, and they overattenuate the de Vries "wiggles". The DC gains can be reduced to more acceptable levels by adjusting model parameters, particularly the sizes of the ocean reservoirs. Better fits to the "wiggles" are also obtained by parameter adjustment. Water content of deep-sea sediments constitutes an extra reservoir for dead carbon, and should help reduce system DC gain.
\end{abstract}

\section{INTRODUCTION}

To further our understanding of the short-term heliomagnetic modulation of atmospheric radiocarbon concentration, we have investigated four models of the radiocarbon exchange system: a 1-box model (Grey and Damon, 1970; fig 1A); 3-box first-order exchange model (eg, Houtermans, Suess, and Oeschger, 1973; fig 1B); 5- and 6-box first-order exchange models (eg, Bacastow and Keeling, 1973; Ekdahl and Keeling, 1973; fig 1C); and a box-diffusion model (Oeschger and others, 1975; fig 1D). Because the 1, 3, 5, and 6-box models are represented by systems of first-order ordinary differential equations, and the partial differential equations of the box-diffusion model can be approximated by first-order ordinary differential equations, all models can be treated as lumped linear systems and are analytically tractable using standard linear system theory.

The difficulty encountered in modeling radiocarbon fluctuations is not only in the complexity of the exchange system itself and determination of the appropriate model, but also in the uncertainties concerning both the input forcing function given by the ${ }^{14} \mathrm{C}$ production rate and the output as measured by the ${ }^{14} \mathrm{C}$ content of the various reservoirs. Different complexities of models have different applications. For example, the simple one-box model was designed solely to model the de Vries "wiggles" during the last 4 to 6 centuries for which solar activity data are available. It is purely a "black box" model that does not pretend to be an analogue of physical process. However, this model is not useful for modeling low frequency phenomena such as geomagnetic dipole moment modulation of ${ }^{14} \mathrm{C}$ concentration where feedback from the oceans becomes important. Also, if the investigator wants to model the uptake of industrial $\mathrm{CO}_{2}$ by various reservoirs, it becomes necessary to explicitly model these reservoirs and specify the nature of the exchange between them. The quality of the 74601

* Present address: Continental Oil Co, Route 3, Box 262, Ponca City, Oklahoma, 
radiocarbon data against which the output of any model must be compared is being improved by new and more precise experimental measurements (eg, Stuiver and Quay, 1980) as well as by improved data analysis for separation of the ${ }^{14} \mathrm{C}$ signal in the presence of noise (see Klein and others, 1980). As predictions of a particular model are compared to these data, the data can be used to constrain or place bounds upon both the models and the production functions used as input. Which data is used again depends on the aim of the study. Some possible constraints are timeseries of ${ }^{14} \mathrm{C}$ fluctuations representing the phenomenon of interest; ${ }^{14} \mathrm{C}$ activity ratios of different reservoirs; or the total radiocarbon inventory, only dependent upon the long-term production function (Sternberg and Damon, 1979). In this paper, we will discuss the use of DC gain as a useful boundary condition.

\section{DC gain}

It is useful to refer to the steady state level of a system output which is attained when the input is held at some fixed value, $i e$, the value $\mathrm{Y}(\mathrm{t}=\infty ; \mathrm{X})$ at which the output from a stable system equilibrates when the input is held at the fixed level $\mathrm{X}$. For a linear system, $\mathrm{Y}(\mathrm{t}=\infty ; \mathrm{X})=$ $\mathrm{g} X$, where $\mathrm{g}$ is the DC gain. The DC gain can be derived from the linear differential equations representing a system by setting all time derivatives equal to zero and other parameters to their DC values.

In the frequency domain, a linear system is completely characterized by a transfer function which relates a selected output and input for each frequency of oscillation $\omega$ such that $\mathrm{Y}(\omega)=\mathrm{H}(\omega) \mathrm{X}(\omega)=|\mathrm{H}(\omega)| \mathrm{e}^{\mathrm{i} \theta(\omega)} \mathrm{X}(\omega)$ where $\mathrm{X}$ is the complex (oscillating) input, $\mathrm{Y}$ is the complex output, $\mathrm{H}(\omega)$ is the complex system transfer function, $|\mathrm{H}(\omega)|$ is the amplitude response function, and $\theta(\omega)$, is the phase shift function. At zero frequency $\mathrm{Y}(\mathrm{O})=$ $\mathrm{H}(\mathrm{O}) \mathrm{X}(\mathrm{O})=\mathrm{gX}(\mathrm{O})$, where all quantities are real. Amplitude responses are often normalized by their DC gains and plotted as $|\mathrm{H}(\omega)| / \mathrm{g}$ vs $\omega$. The transfer function $\mathrm{H}(\omega)$ is found by solving the differential equations specifying the system for a harmonic input, or by taking the Fourier transform of the equations.

In reservoir modeling of atmospheric ${ }^{14} \mathrm{C}$ fluctuations, we can separate the production rate $Q$ and the atmospheric ${ }^{14} \mathrm{C}$ content $\mathrm{N}_{\mathrm{a}}{ }^{*}$ into $\mathrm{DC}$ and variable parts: $\mathrm{Q}(\mathrm{t})=\bar{Q}_{\mathrm{o}}+\Delta \mathrm{Q}(\mathrm{t}) ; \mathrm{N}_{\mathrm{a}}{ }^{*}(\mathrm{t})=\overline{\mathrm{N}}_{\mathrm{a}}{ }^{*}+\mathrm{N}_{\mathrm{a}}{ }^{*}(\mathrm{t})$; such that $\overline{\mathrm{N}}_{\mathrm{a}}{ }^{*}=\mathrm{g} \overline{\mathrm{Q}}$ or $\mathrm{g}=\overline{\mathrm{N}}_{\mathrm{a}}{ }^{*} / \overline{\mathrm{Q}}$, where $\overline{\mathrm{N}}_{\mathrm{a}}{ }^{*}$ is the output equilibrium ${ }^{14} \mathrm{C}$ content of the atmosphere at the constant production rate $\bar{Q}$. Many ${ }^{14} \mathrm{C}$ modeling problems are only concerned with the relative amplitude of $\mathrm{N}_{\mathrm{a}}{ }^{*}(\mathrm{t})$ as a per mil fluctuation relative to the value calculated at a reference year, usually AD 1890. In this case, if the reference activity is calculated from the model, then the DC gain, which is essentially a scaling factor, is not of first-order importance. If one calculates the absolute activities or uses the observed activity at the reference year, the DC gain must be considered and there will be one less degree of freedom in the modeling process. This loss of freedom usually means specification of the total carbon content of the various reservoirs rather than the relative amounts. 
A.

I-BOX MODEL

Grey and Damon

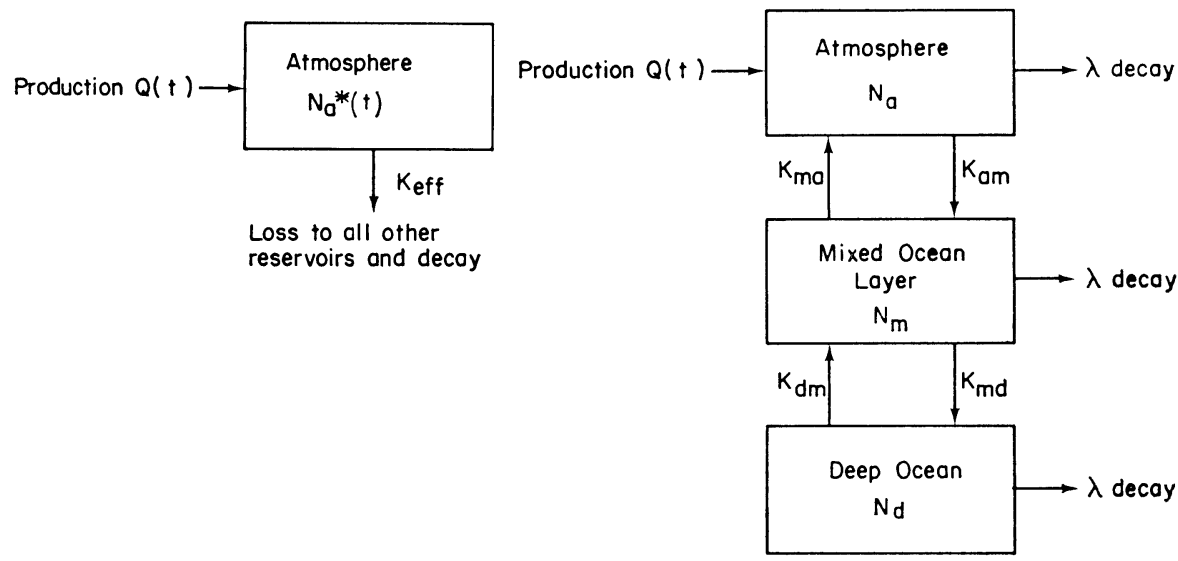

C.

SIX-BOX EXCHANGE MODEL Ekdahl and Keeling

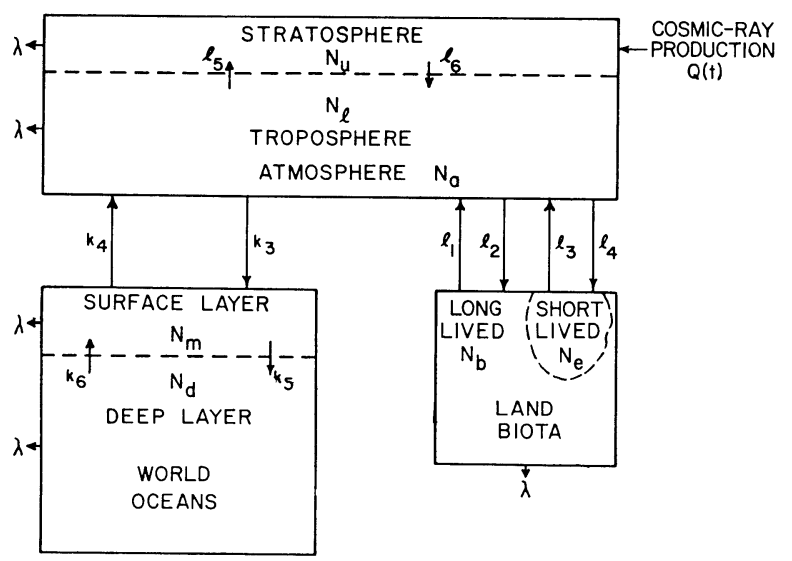

Fig 1. Radiocarbon reservoir models. A) One-box model with atmospheric radiocarbon content $\mathrm{N}_{\mathrm{a}} *$. Standard parameter: $\mathrm{K}_{\mathrm{ert}}=1 / 100$. B) Three-box first-order exchange model. $N_{1}$ is total carbon content in reservoir $i$. Standard parameters: $K_{a m}=1 / 7.3$, $\mathrm{K}_{\mathrm{dm}}=1 / 1000, \mathrm{~N}_{\mathrm{m}} / \mathrm{N}_{\mathrm{a}}=1.3, \mathrm{~N}_{\mathrm{d}} / \mathrm{N}_{\mathrm{a}}=61.7$. C) Six-box first-order exchange model. This simplifies to the five-box model if the stratosphere and troposphere are combined.

Standard parameters: $l_{2}=1 / 24, l_{1}=1 / 21, l_{5}=1 / 2, \mathrm{~K}_{3}=1 / 6, \mathrm{~K}_{0}=1 / 1500, \mathrm{~N}_{\mathrm{v}} / \mathrm{N}_{2}=0.15$, $\mathrm{N}_{1} / \mathrm{N}_{\mathrm{a}}=0.85, \mathrm{~N}_{\mathrm{o}} / \mathrm{N}_{\mathrm{a}}=0.12, \mathrm{~N}_{\mathrm{b}} / \mathrm{N}_{\mathrm{a}}=2.52, \mathrm{~N}_{\mathrm{m}} / \mathrm{N}_{\mathrm{a}}=2.0, \mathrm{~N}_{\mathrm{d}} / \mathrm{N}_{\mathrm{a}}=61.0$. 
D.

\section{BOX DIFFUSION MODEL \\ Oeschger et al.}

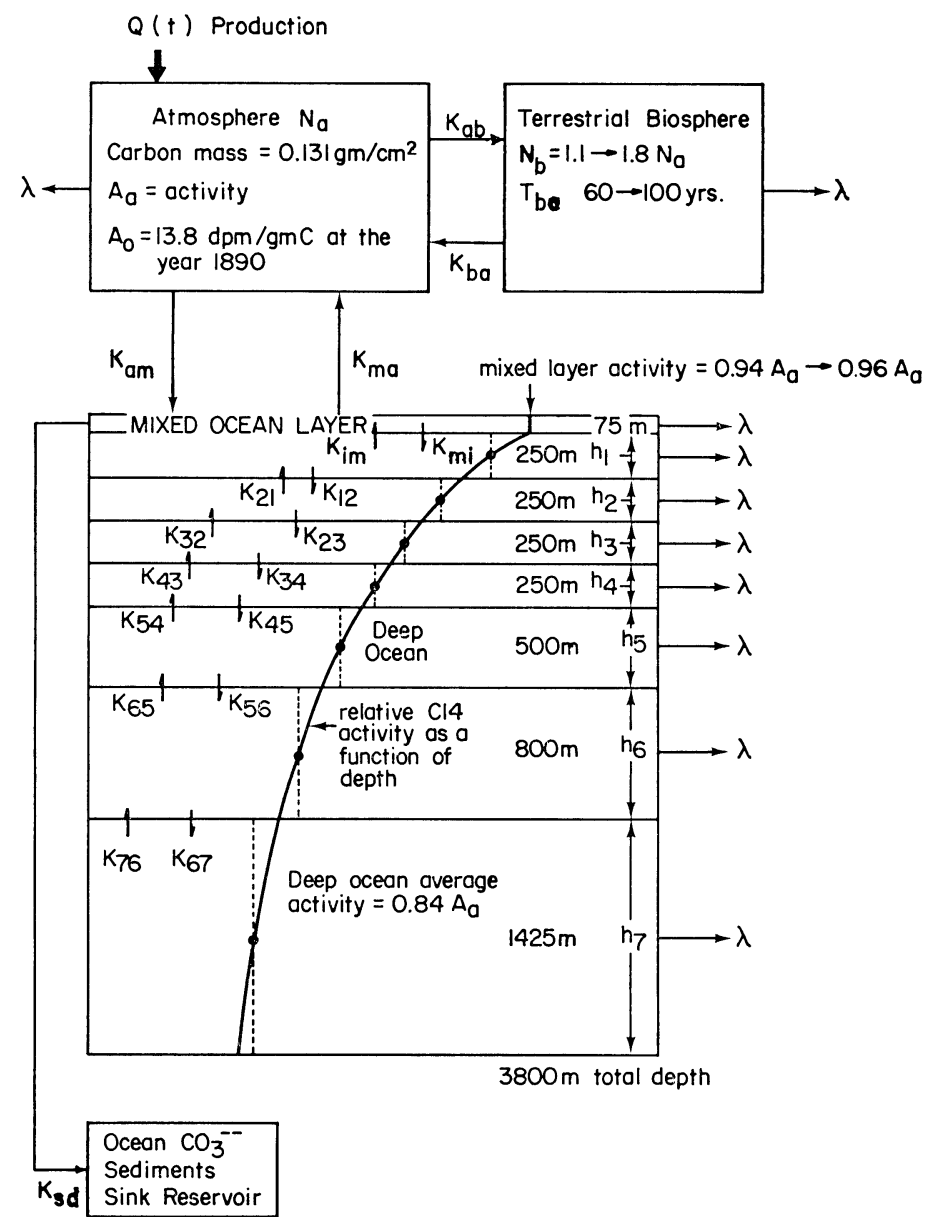

D). Box-diffusion model. Diffusion into deep sea is approximated by first-order exchange between the mixed layer and seven deep ocean reservoirs. Standard parameters: $\mathrm{K}_{\mathrm{am}}=1 / 7.3, \mathrm{~K}_{\mathrm{ab}}=1 / 33, \mathrm{~K}_{\mathrm{sd}}=1 / 5000$, eddy diffusion constant $\mathrm{K}=3980$ $\mathrm{m}^{2} / \mathrm{yr}, \mathrm{N}_{\mathrm{b}} / \mathrm{N}_{\mathrm{a}}=1.8$ 
Let us now calculate the "observed" DC gain. The 10 percent peakto-peak long-term variation of atmospheric ${ }^{14} \mathrm{C}$ content is a relatively small perturbation of DC conditions (Sternberg and Damon, in press). Although we do not actually observe the DC state, we can estimate DC gain from the known long-term ${ }^{14} \mathrm{C}$ and geomagnetic changes. Considering the uncertainties in the modeling process and the frequent assumption of steady state to calculate return carbon exchange from one reservoir to another, (eg, Sternberg and Damon, in press) we believe this estimate is valid. The ${ }^{14} \mathrm{C}$ activity of the atmosphere in the year $\mathrm{AD} 1890$ was $\mathrm{A}_{\mathrm{a}}=14.1 \pm 0.1$ $\mathrm{dpm} / \mathrm{gC}$ (Damon, Lerman, and Long, 1978), and the long-term variation of ${ }^{14} \mathrm{C}$ activity indicates that $\bar{A}_{\mathrm{a}} \approx 1.04 \mathrm{~A}_{\mathrm{a}}$ (1890). Using the value $\mathrm{N}_{\mathrm{a}}=$ $0.121 \pm .004 \mathrm{gC} / \mathrm{cm}_{\mathrm{e}}{ }^{2}$ for the pre-industrial atmospheric total carbon (Oeschger and others, 1975) and $\mathrm{a}^{14} \mathrm{C}$ half-life of $\mathrm{T} 1 / 2=5730 \pm 40$ years (Godwin, 1962, the ${ }^{14} \mathrm{C}$ mass of the atmosphere will be $\bar{N}_{\mathrm{a}}{ }^{*}=\overline{\mathrm{A}}_{\mathrm{a}} \mathrm{N}_{\mathrm{a}} \overline{\mathrm{T}}$, where the ${ }^{14} \mathrm{C}$ mean-life $\overline{\mathrm{T}}=\mathrm{T} 1 / 2 / .693$. For the three solar cycles covering 1937 to 1967 , the average ${ }^{14} \mathrm{C}$ production rate was $132 \pm 24{ }^{14} \mathrm{C}$ atoms/ $\mathrm{cm}_{\mathrm{e}}{ }^{2} / \mathrm{min}$ (Lingenfelter and Ramaty, 1970). Long-term changes in the production rate are primarily governed by geomagnetic shielding. Because the present geomagnetic dipole moment is nearly equal to the average value of its 10,000-year quasi-sinusoidal variation, we can set $\bar{Q}$ equal to the recent average over several solar cycles. Thus, we can approximate the observed DC gain as:

$\mathrm{g}_{\mathrm{obs}}=\frac{\overline{\mathrm{N}}_{\mathrm{a}}^{*}}{\mathrm{Q}}=\frac{1.04(14.1 \pm 0.1)(0.121 \pm .001)(5730 \pm 40)}{.693(132 \pm 24)}=111 \pm 22$ years.

Houtermans, Suess, and Oeschger (1973) used the concept of DG gain to calculate parameter values for the 3-box model based on parameter values used for a 2-box model. The "observed" DC gain, as calculated above, can now be similarly used as a constraint on all carbon exchange models and the values used for the relevant parameters.

\section{Model predictions of de Vries "wiggles"}

For the simple one-box model, ${ }^{14} \mathrm{C}$ production is input to the atmosphere as the forcing function and transfer to all other reservoirs as well as losses to radioactive decay are lumped into a single effective first-order rate coefficient $K_{\text {eff }}$, or residence time $T_{\text {eff }}=1 / K_{\text {eff }}$. The model is described by a single first-order linear differential equation:

$$
\frac{\mathrm{dN}_{\mathrm{a}}{ }^{*}(\mathrm{t})}{\mathrm{dt}}=-\mathrm{K}_{\mathrm{eff}} \mathrm{N}_{\mathrm{a}}^{*}(\mathrm{t})+\mathrm{Q}(\mathrm{t}) \text {. }
$$

The DG gain for this system is $g_{1}=T_{\text {eff }}$. In using the one-box model to study the de Vries effect for the period of time for which sunspot data are available, Grey and Damon (1970) used the relationship of Lingenfelter (1963) between the annual sunspot number and the annual ${ }^{14} \mathrm{C}$ production. Model predictions best matched the ${ }^{14} \mathrm{C}$ data using a value for $T_{\text {eff }}$ of 100 years, and rather good agreement with ten-year averages of the raw data was obtained. Ekdahl and Keeling (1973) have criticized this model as being too simple a system to be realistic and have questioned the use 
of an adjustable parameter chosen to best fit the data. However, we have shown above that $T_{\text {eff }}$ has physical significance where $g_{1}=T_{\text {eff }}$, so that the value of $g_{1}=100$ years chosen to best fit the data is, within limits of accuracy, equal to the "observed" value $g_{o b ;}=111 \pm 22$. In fact, Grey and Damon originally found the model predictions insensitive to values of $\mathrm{T}_{\text {eff }}>100$, and we have found the amplitude response for periods of 10 to 100 years similarly insensitive. Thus, a value of $T_{\text {eff }}$ equal to $g_{o b}$ might be more appropriate. It seems that this simple model somehow does describe the effective lumped physical processes affecting ${ }^{14} \mathrm{C}$ activity.

Results of our attempts to model the de Vries effect using the other models will be described in more detail in a future paper. We modified the box-diffusion model of Oeschger and others (1975) so that the biota is a first-order exchange reservoir rather than a fixed delay line, and we have added a sedimentary sink. Using standard parameter values from the original authors, attenuation for this model between periods of 10 to 100 years is greater than the one-box model, so the de Vries "wiggles" are not matched quite as well, although a good correlation is still evident. The 3 , 5, and 6-box models over-attenuate to an even greater extent when evaluated with their standard parameters. The flat response of the fivebox model showing none of the 18th and 19th century de Vries effect "wiggles" (Bacastow and Keeling, 1973) provides a dramatic illustration of this over-attenuation when compared with the one-box model. These models can be optimized empirically to achieve a better fit to the data by performing sensitivity tests on the amplitude response function with respect to changes of the various parameters. By optimizing the five-box model we were able to reduce the attenuation, but not so much as to match the response of the one-box model.

\section{DG gain as a constraint on ${ }^{14} \mathrm{C}$ models}

To model the de Vries effect, a new $Q$ vs sunspot number relationship was derived using data from Lingenfelter and Ramaty (1970). Revised sunspot data accounting for the Maunder minimum (Eddy, 1976) were used. The lower solar activity for the period AD 1645 to 1715 leads to a higher ${ }^{14} \mathrm{C}$ production than would be produced by a steady 11-year solar cycle like we have today, The response of the one-box model to this forcing function is in good agreement with the ${ }^{14} \mathrm{C}$ data. However, the more complex models show a buildup of ${ }^{14} \mathrm{C}$ in the atmosphere for the early 18th century far in excess of what the data show. This buildup may be partly due to the initial conditions used, but it seems to be primarily a DC gain problem. That is, for the production rate used, the models are outputting too much ${ }^{14} \mathrm{C}$ to be funneled through the atmosphere and into the other reservoirs. For standard parameters (given in fig 1), the steady state gains are greater than 150 for the 3, 5, and 6-box models and 133 for the box-diffusion model. These are all higher than $\mathrm{g}_{\text {obs }}$. There are two ways to resolve this discrepancy between calculated and observed DC gains. Either the calculation for $\mathrm{g}_{\mathrm{ob} ;}$ is wrong and $\mathrm{g}_{\mathrm{obs}}$ should in fact be higher, or the reservoir models are incorrect and should be modified so as to lower the DC gains. Since $\mathrm{g}_{\mathrm{obs}}=\overline{\mathrm{N}}_{\mathrm{2}}{ }^{*} / \bar{Q}$, a lowering of $\bar{Q}$ would in- 
crease $\mathrm{g}_{\mathrm{obs}}$. Using the more complex models and keeping the reservoir parameters within reasonable physical limits, it was difficult to sufficiently control the ${ }^{14} \mathrm{C}$ buildup in the atmosphere through reservoir adjustment alone. A reduction of $\bar{Q}$ by as much as 20 percent markedly improves the situation. Stuiver and Quay (1980) also found a reduction in $\bar{Q}$ is necessary to obtain stability in the box-diffusion model. However, such a reduction in the production rate does not seem to be required by modeling of other ${ }^{14} \mathrm{C}$ phenomena. The total radiocarbon content of all reservoirs, or radiocarbon inventory, is only depedent upon the long-term ${ }^{14} \mathrm{C}$ production. Using a $\bar{Q}$ nearly equal to that used above to calculate $\mathrm{g}_{\mathrm{ob} \text {; }}$, Sternberg and Damon (in press) computed a theoretical inventory very close to that found by Damon, Lerman, and Long (1978) by evaluating the contents of the various reservoirs.

We have not yet resolved all these problems. A complicating factor is the increasing number of parameters for the more complex models. This highlights one of the advantages of the "black-box" approach of the simple one-box model. All model parameters cannot be varied independently; eg, if the carbon contents of two exchanging reservoirs are fixed along with one of the exchange rate coefficients, the other exchange rate may not be fixed independently. Furthermore, if a model parameter is varied so as to change the DC gain of the model, the shape of the amplitude response function and, hence, the attenuation at higher frequencies may also change. Although the pattern we have seen indicates that a higher DC gain tends to increase attenuation for periods in the 10 to 100 year band, this is probably not true in general. It should lastly be emphasized that if a particular problem ever requires an input of $g_{o b s}=\bar{N}_{\mathrm{a}}{ }^{*} / \bar{Q}$, this must be done such that $\mathrm{g}_{\mathrm{obs}}=\mathrm{g}$ calculated for the model, otherwise an inequality will be introduced.

It is worthwhile to isolate the sensitive parameters in the $\mathrm{DC}$ gain formulas. We have already seen that for the one-box model, $g_{1}=1 / K_{\text {eff }}$

$=\mathrm{T}_{\text {eff. }}$. For the three-box model, $\mathrm{g}_{3}=\frac{1}{\mathrm{~K}_{\mathrm{am}}}+\frac{\alpha_{\mathrm{a} / \mathrm{m}}}{\mathrm{R}_{\mathrm{d}}}\left(\frac{1}{\mathrm{~K}_{\mathrm{dm}}}+\frac{1}{\lambda}\right)$,

where $R_{d}=N_{d} / N_{a}$ is the ratio of total carbon in the deep sea to the atmosphere, $\alpha_{\mathrm{a} / \mathrm{m}}$ is the atmosphere to deep-sea fractionation factor, and other terms are explained in figure 1. Houtermans, Suess, and Oeschger (1979, eq 16) express $\mathrm{g}_{3}$ differently with a complex expresssion explicitly including total carbon content of all reservoirs. Although such an expression might be difficult to find for other models, it usefully includes a parameter that will affect the DC gain without affecting the shape of the spectral response. For the six-box model,

$$
\mathrm{g}_{6}=\frac{l_{5} /\left(l_{5}+\lambda\right)}{\left(l_{2}+l_{4}+l_{6}+\mathrm{K}_{3}+\lambda\right)-\frac{l_{1} l_{2}}{l_{1}+\lambda}-\frac{l_{3} l_{4}}{l_{3}+\lambda}-\frac{l_{5} l_{6}}{l_{5}+\lambda}-\frac{\mathrm{K}_{3} \mathrm{~K}_{4}\left(\mathrm{~K}_{6}+\lambda\right)}{\left(\mathrm{K}_{4}+\mathrm{K}_{5}+\lambda\right)\left(\mathrm{K}_{6}+\lambda\right)-\mathrm{K}_{5} \mathrm{~K}_{6}}}
$$

where the exchange rates are ${ }^{14} \mathrm{C}$ rates and fractionation factors are not explicitly shown. This reduces to the five-box model as $l_{5} \rightarrow 0$ and $l_{6} \rightarrow \infty$. 
By using the relations $l_{1}>>\lambda, l_{3}>>\lambda$ and $l_{5}>>\lambda$, the above expression will reduce to

$$
\mathrm{g}_{6} \approx \frac{1}{\mathrm{~K}_{3}}+\frac{\alpha_{\mathrm{a} / \mathrm{m}}}{\mathrm{R}_{\mathrm{d}}}\left(\frac{1}{\mathrm{~K}_{6}}+\frac{1}{\lambda}\right) .
$$

Exchange rates are now for stable carbon and the fractionation factor has been made explicit. Since $\mathrm{K}_{3}=\mathrm{K}_{\mathrm{am}}$, and $\mathrm{K}_{6}=\mathrm{K}_{\mathrm{dm}}$ this expression is the same as that for the three-box model. The addition of a biosphere does not appreciably affect $g$, as we would expect for a rapidly exchanging reservoir. Similarly, with the assumption that $\mathrm{K}_{\mathrm{ba}}>>\lambda$ and $\mathrm{K}_{\mathrm{ma}}>>\mathrm{T}_{1}$, the DC gain for the box diffusion model is

$$
\mathrm{g}_{\mathrm{diff}} \approx \frac{1}{\lambda\left(\mathbf{l}+\mathrm{R}_{\mathrm{b}}\right)+\mathrm{R}_{\mathrm{m}} \mathbf{T}_{1}}
$$

where $R_{b}=N_{b} / N_{a}, R_{m}=N_{m} / N_{a}$ and $T_{1}=\lambda+K_{d}+\frac{K \lambda}{h_{m}} \frac{\sinh \left(2 h_{1 d} \sqrt{\frac{\lambda}{K}}\right)}{1+\cosh \left(2 h_{d} \sqrt{\frac{\lambda}{K}}\right)}$.

$\mathrm{K}$ is the eddy diffusion constant. Sensitivity tests indicate that $\mathrm{g}_{\mathrm{diff}}$ is not sensitive to changes in $K, R_{b}$ or $K_{s d}$ but it is critically dependent on $h_{d}$, $h_{m}$ and $R_{m}$. Thus, the sizes of the deep-sea and mixed layer reservoirs are dominant.

SUMMARY

A necessary but not sufficient condition for validity of a ${ }^{14} \mathrm{C}$ reservoir model is that the DC gain of the model should be equal to the "observed" DC gain, $\mathrm{g}_{\mathrm{obs}}=\overline{\mathrm{N}}_{\mathrm{a}} * / \bar{Q}$, within the limits of uncertainty of $\mathrm{g}_{\mathrm{obs} \text {. }}$. The DC gain is important as a scaling factor for calculation of absolute, as opposed to relative, activities.

Four models were compared for their ability to match the de Vries "wiggles" from AD 1700 to 1900 . The curve predicted by the one-box model shows excellent agreement with the data. The more complex 3-box, 5-, and 6-box, and box-diffusion models have a tendency to cause an initial buildup of atmospheric ${ }^{14} \mathrm{C}$ and to attenuate the predicted "wiggles" so as not to match the data as well as the 1-box model. The buildup problem occurs because the DC gains of the models are larger than $g_{o b s}$. By reducing the production rate, $g_{\mathrm{obs}}$ can be raised, but previous modeling of the ${ }^{14} \mathrm{C}$ inventory gave no strong evidence that the higher production rate is invalid. Another way to resolve the inequality between model DC gains and $g_{\text {obs }}$ is to alter the model. The DC gains for all multi-box models are critically dependent upon the size of the deep sea and the gains can be sufficiently lowered by postulating a larger than previously accepted size for the deepsea reservoir. The size of the mixed layer is also critical. Parameters affecting the DC gain to a lesser extent are the rate coefficients for ${ }^{14} \mathrm{C}$ transfer to the mixed layer, the size of the biosphere reservoir and the eddy diffusion coefficient in the box-diffusion model. Addition of a sedimentary sink also helps to reduce DC gain. 
A factor that has been ignored so far in ${ }^{14} \mathrm{C}$ reservoir modeling is the water content of sediments, which may equal a significant fraction of the water mass of the oceans (Poldervaart, 1955). Unconsolidated sediments are saturated with water and gradually, with compaction, lose their water which streams back to the ocean carrying "dead" carbon. In addition, ${ }^{14} \mathrm{C}$ decay and carbon precipitation will lead to a concentration gradient in the aqueous pore space medium that will increase the effective size of the oceans. Both effects would tend to decrease the DC gains for the complex models. We hope to model this reservoir explicitly in future work.

The over-attenuation by the complex models has been partly rectified through parameter adjustment so that there is reasonable correlation with the de Vries "wiggles". Changing the model parameters can have varied effects on the DC gain and attenuation at higher frequencies, and we hope to find an optimal way to change parameters so as to improve both characteristics.

Lastly, the one-box model, although essentially a "black box" model, has a theoretically justifiable basis in that the DC gain $g_{1}=T_{\text {eff }} \approx g_{\text {ob: }}$. The one-box model is also easier to handle and requires fewer assumptions, so for some purposes, would be the preferable model. It is, however, useless if a mechanistic model is required, a statement that is also true of all thermodynamic systems.

\section{ACKNOWLEDGMENTS}

Financial support for this work was supplied by the State of Arizona and National Science Foundation grants EAR-78-21813 to Paul Damon and EAR-77-22340 to Robert Butler of this department.

\section{Note added:}

In the poster session, considerable time was spent in discussion of the use of the radiocarbon concentration of the atmosphere as a scaling factor. For example, in the paper by Stuiver and Quay (1980), they input a value of $\bar{Q}=1.57 \mathrm{a} / \mathrm{sec} / \mathrm{cm}^{2}$. Using standard parameters, the $\mathrm{DC}$ gain of the box-diffusion model is 130. Therefore, the model as used by Stuiver and Quay outputs an unacceptably low steady state atmospheric ${ }^{14} \mathrm{C}$ activity of $11.5 \mathrm{dpm} / \mathrm{gC}$. As a scaling factor alone, we agree that this only reduces the $\Delta$ wiggles by a factor of $11.5 / 14.1$ or 0.81 . As pointed out by Lazear, Damon, and Sternberg (1980), this may not be serious unless one is working with absolute activity rather than relative amounts or unless the model implicitly involves a serious inequality between production, absolute activity, and DC gain.

On the other hand, the 5- and 6-box models of Bacastow and Keeling (1973), yield very high DC gains with standard parameters. For example, their five-box model yields a DC gain of 157 . With $\bar{Q}$ of $2.2 \mathrm{dpm} / \mathrm{gC}$, this yields a steady state atmospheric ${ }^{14} \mathrm{C}$ activity of $18.5 \mathrm{dpm} / \mathrm{gC}$ which is unacceptably high.

Dr Stuiver objected to our statement that all of the multi-box models, as now parameterized, over-attenuate the heliomagnetic modulation of ${ }^{14} \mathrm{C}$ activity. A more precise statement would be that either the multi-box 
models over-attenuate or the forcing function of Lingenfelter and Ramaty (1970) is not correct. Stuiver and Quay prefer the latter explanation. Our point is that one must be sure before arriving at such an important conclusion that the model used is mechanistically acceptable and correctly parameterized. In other words we prefer, for the moment to play the role of the "Devil's Advocate".

\section{REFERENCES}

Bacastow, R and Keeling, C D, 1973, Atmospheric carbon dioxide and radiocarbon in the natural carbon cycle. II. Changes from AD 1700 to 2070 as deduced from a geochemical model, in Woodwell, G M, and Pecan, E V, eds, Carbon and the biosphere, Brookhaven symposium in biology, 24th, Proc: Upton, N Y, 1972: USAEG
Conf-720510, p 86-135.

Damon, P E, Lerman, J C, and Long, Austin, 1978, Temporal fluctuations of atmospheric ${ }^{14} \mathrm{C}$ : causal factors and implications, in Annual review of earth and planetary
sciences: Ann Rev Inc, Palo Alto, Calif, p 457-494.

Eddy, J A, 1976, The sun since the Bronze age, in Williams, P J, ed, Physics of solar planetary environments: Am Geophys Union, v 2, p 958-972.

Ekdahl, C A and Keeling, C D, 1973, Atmospheric carbon dioxide and radiocarbon in the natural carbon cycle: I. Quantitative deductions from records at Mauna Loa observatory and at the South Pole, in Woodwell, G M, and Pecan, E V, eds, Carbon and the biosphere, Brookhaven symposium in biology, 24th, Proc: Upton, N Y,
1972 , USAEC Conf-720510, p 51-85.

Godwin, Harry, 1962, Half-life of radiocarbon: Nature, v 195, no. 4845, p 984.

Grey, D C and Damon, P E, 1970, Sunspots and radiocarbon dating in the Middle Ages, in Berger, Rainer, ed, Scientific studies in Medieval archaeology: Berkeley, Univ
California Press, p 167-182.

Houtermans, J C, Suess, H E, and Oeschger, Hans, 1973, Reservoir models and production rate variations of natural radiocarbon: Jour Geophys Research, v 78, no. 12,
p 1897-1908.

Klein, Jeffrey, Lerman, J C, Damon, P E, and Linick, Timothy, 1980, Radiocarbon concentration in the atmosphere: 8000 -year record of variations in tree-rings. First results of a USA workshop, in Stuiver, Minze and Kra, Renee, eds, Internatl radiocarbon conf, 10th, Proc: Radiocarbon, v 22, no. 3, p 950-961.

Lingenfelter, R E, 1963, Production of carbon-14 by cosmic-ray neutrons: Rev Geophysics, v 1, no. 1, p 35-55.

Lingenfelter, R E and Ramaty, R, 1970, Astrophysical and geophysical variations in $\mathrm{C}^{14}$ production, in Olsson, I U, ed, Radiocarbon variations and absolute chronology, Nobel symposium, 12th, Proc: New York, John Wiley \& Sons, p 513-537.

Oeschger, Hans, Siegenthaler, Ulrich, Schotterer, Ulrich, and Gugelmann, A, 1975, A box diffusion model to study the carbon dioxide exchange in nature: Tellus, $v 27$, no. 2 p 168-192.

Poldervaart, A, 1955, Chemistry of the earth's crust, in Poldervaart, A, ed, Crust of the earth: Geol Soc America spec paper 62, p 119-144.

Sternberg, R S and Damon P E, 1979, Sensitivity of radiocarbon fluctuations and inventory to geomagnetic and reservoir parameters, in Berger, Rainer and Suess, Hans, eds, Radiocarbon dating, Internatl conf on radiocarbon dating, 9th, Proc: Berkeley/Los Angeles, Univ California Press, p 691-720.

Stuiver, Minze and Quay, P D, 1980, Changes in atmospheric ${ }^{14} \mathrm{C}$ attributed to a variable sun: Science, v 207, p 11-19. 